\title{
A numerical parametric study on the plate inclination angle of steel plate shear walls
}

\author{
M. Gürbüz, İ. Kazaz* \\ Erzurum Technical University, Civil Engineering Department, Erzurum, Turkey
}

\begin{abstract}
In this study, tension field inclination angle $(\alpha)$, which forms on thin steel plate of steel plate shear walls, is investigated. For this purpose, nonlinear finite element models of selected experimental steel plate shear wall specimens in literature were created. Afterwards, the results of the nonlinear analyses of finite element models and the results of experimental investigations were compared and a good agreement was attained. After creating and validating the models, the correlation of the inclination angle with different plate parameters such as plate thickness, boundary elements stiffness, width to height ratio of walls were studied. Steel plate shear walls with different aspect ratios were modelled and various boundary element cross sectional areas and plate thicknesses were used. It was observed that inclination angle is not very sensitive to plate thickness and boundary element cross sectional areas, but aspect ratios have an apparent effect on the tension field inclination angle. The analysis results showed that the inclination angle takes almost a constant value above 0.01 drift ratio. Moreover, it is observed that the tension field inclination angle develops mostly between $35^{\circ}-45^{\circ}$.
\end{abstract}

\section{Keywords}

Steel plate shear walls; Inclination angle; Tension field; Finite element model

Received: 19 December 2018; Accepted: 11 January 2019

ISSN: 2630-5763 (online) (C) 2018 Golden Light Publishing® All rights reserved.

\section{Introduction}

Steel plate shear walls (SPSW) have a wide range of use from low-rise residential buildings to high rise buildings. Steel plates referred as "infill plates" in this study. The infill plate is designed to resist all lateral loads on a structural system. Corresponding to shear force, a tension field forms on infill plate. SPSW systems are similar to that of a vertically cantilevered plate girder. The analogy between steel plate shear wall system and a plate girder helps to understand the behavior of SPSW but system mechanisms are not completely the same [1]. Steel plate shear walls are designed as primary dynamic lateral load resisting systems. However, steel plates have a stability problem at the very beginning. The buckling resistance of an infill plate is negligible since the shear buckling of infill plate occurs at very low force levels. But, buckling of the steel plate is not a failure mechanism for the structural system. Diagonal buckling fields form under lateral loads and these fields exposed to tension forces. The angle between buckled tension fields and vertical is defined as inclination angle. This angle is a parameter used in the design of steel plate shear walls. To calculate the inclination angle, AISC 341 suggests a formulation based on the study Timler and Kulak [2]. The inclination angle given as follows;

\footnotetext{
Corresponding author

E-mail: ilkerkazaz@erzurum.edu.tr
} 


$$
\tan ^{4} \alpha=\frac{1+\frac{t L}{2 A_{c}}}{1+\operatorname{th}\left(\frac{1}{A_{b}}+\frac{h^{3}}{360 I_{c} L}\right)}
$$

where $L=$ plate length, $t=$ plate thickness, $h=$ plate height, $A_{c}=$ column cross sectional area, $A_{b}=$ beam cross sectional area, $I_{c}=$ moment of inertia of the column.

Researchers investigated tension field inclination angle analytically and experimentally. Timler and Kulak [2] used strain gauges on their experiments and reported that the inclination angle varies from $46.6^{\circ}$ to $53.2^{\circ}$. Elgaaly et al. [3] used finite element models to investigate the inclination angle and indicated that the angle between the middle - plate shell element principal stresses and vertical is ranged from $40^{\circ}$ to $50^{\circ}$. Driver et al. [4] compared experimental and finite element model results and stated that the inclination angle obtained from both experimental and numerical studies varied between $42^{\circ}$ and $50^{\circ}$. Shake table test conducted by Rezai [5] showed that principal stress angles with vertical vary between $37^{\circ}$ and $42^{\circ}$ at mid plate and between $30^{\circ}$ and $38^{\circ}$ at the base field. Kharrazi [6] indicates that principal stress vectors of finite element models differ from $34^{\circ}$ to $40^{\circ}$. When yield force applied on models, the angle $\alpha$ takes values between $34^{\circ}$ and $40^{\circ}$. Choi et al. [7] revealed that models with different aspect ratios have an inclination angle between $24^{\circ}$ and $45^{\circ}$. Some other researchers focused on different mechanisms of steel plate shear walls. Ozcelik and Clayton [8] presented an equation that is proposed for partial tension field inclination angle of beam connected steel plate shear walls. Wei et al. [9] stated that an inclination angle of approximately $45^{\circ}$ was observed for partially connected steel plate shear walls.

In this study, a general-purpose finite element computing program ANSYS APDL has been used to investigate the correlation between selected parameters and tension field inclination angle. By using ANSYS software, detailed three-dimensional models were generated. The software offers elastic linear and nonlinear analysis capabilities under the static and dynamic loading conditions. Selected experimental works from literature have been studied to validate the finite element modeling approach. After validating the models, a parametric study was conducted to investigate the tension field inclination angle sensitivity over the parameters given in Equation (1). The study aims to investigate the tension field inclination angle formation with different boundary elements, steel plate thickness and frame aspect ratios. Also, it is studied whether a constant tension field angle can be used in design process or not.

Selected experimental steel plate models are Lubell's [10] SPSW2, Berman and Bruneau's F2 [11] and Wang et al.'s TM2 [12]. Only one specimen per study is selected and modelled for verification of results. For validation of the finite element models, experimental loading protocols as proposed by ATC-24 was used [13]. ATC-24 is a recommendation for testing components of steel structures under cyclic loading conditions. ATC-24 recommends to start testing in a force-controlled manner till an observed global yield. Before the observed yield, at least six cycles are recommended. After the yield displacement is identified, larger peak deformations should be applied with multiple repetitions. For further details readers may refer to original studies cited here. For parametric study, a loading plate is created at the top left of the model and displacement-controlled loading is applied.

\section{Finite element modelling}

\subsection{Finite elements and material model}

SHELL 181 finite element was chosen from ANSYS element library as the element type [14]. SHELL 181 is defined at ANSYS library as a suitable element to model thin to moderately-thick shell structures. The element is a four-noded element with six degrees of freedom at each node: translations in the $\mathrm{x}, \mathrm{y}$, and $\mathrm{z}$ directions, and rotations about the $\mathrm{x}, \mathrm{y}$, and $\mathrm{z}$ axes. Also, SHELL 181 element is suitable for large strain nonlinear applications. 
All elements of the model were considered as isotropic. Rate-independent material model was selected because it was assumed that the material response is not dependent on the rate of the loading. The material was established as elastoplastic and von Misses yield criterion was used. Kinematic hardening rule was adopted for the models. According to kinematic hardening rule, the yield surface remains constant in size and translates in the direction of yielding. Moreover, multilinear stress - strain curves were defined as the material data input.

For parametric study, the yield strength and maximum strength of steel plate web plate were defined as $\sigma_{y p}=320 \mathrm{MPa}$ and $\sigma_{u p}=450 \mathrm{MPa}$ respectively. Besides, the yield strength and maximum stress of the boundary elements were specified as $\sigma_{y b}=380 \mathrm{MPa}$ and $\sigma_{u b}=525 \mathrm{MPa}$ respectively. Elasticity module is $200 \mathrm{GPa}$ and Poisson's ratio is 0.30 . Density of steel is 7850 $\mathrm{kg} / \mathrm{m}^{3}$.

Boundary conditions for validation models were directly taken from experiments. For parametric study, rigid column-beam connections were used. Also, for all finite element models, all nodes fixed at the base level. Then, to obtain fully yielded steel plate webs and prevent beam buckling, double beams used at the top of the models.

\subsection{Convergence issues}

Convergence problems play a key role in nonlinear finite element analysis. To obtain a proper solution, convergence problems should be overcome without interfering to program defined convergence limits. In this study, convergence problems occurred during the nonlinear solutions. To overcome those problems, a couple of procedures were adopted. In example, using smaller load steps and optimization of the element mesh size are some effective procedures to avoid non-converged solutions. Fig. 1 shows out of plane displacement at 0.05 drift ratio of the same steel plate shear wall finite element model with different mesh sizes.

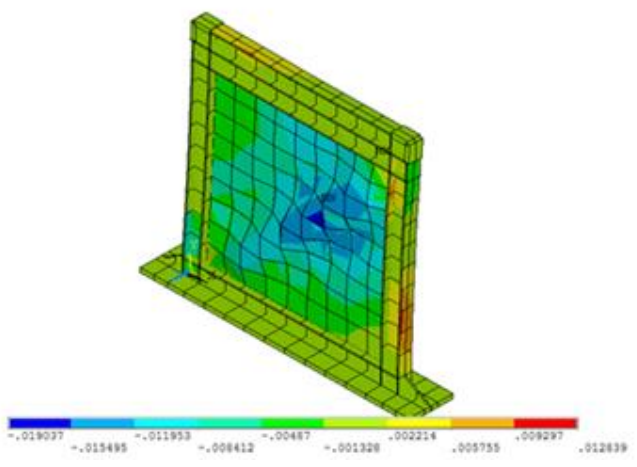

a) 380 elements

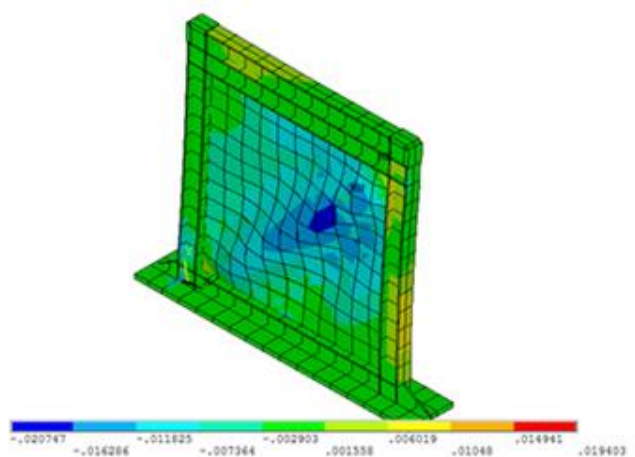

b) 470 elements

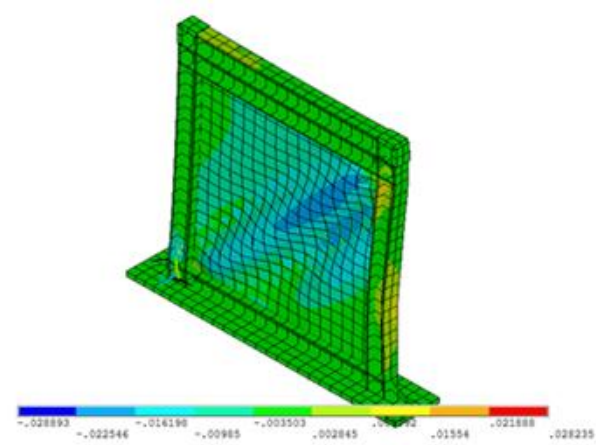

c) 1007 elements

Fig. 1. Out of plane displacement at 0.05 drift ratio of the same model with different mesh sizes 
It is not a practical solution to use too fine element mesh size or using too small-time steps to obtain converged solution. To have an economic solution, storage usage and total analysis time should be considered. In other words, an optimization should be made to have a practical analysis. In example, Lubell [10] SPSW2 test is modelled and analyzed for this study. Total analysis time was less than five minutes with an Intel i7 (8 $\mathrm{GB} \mathrm{ram} / 3,6 \mathrm{GHz}$ ) computer.

\subsection{Analysis}

To validate the results three different steel plate shear wall systems were selected. Selections have been made according to the system mechanisms.
All selected experimental models represent different structural mechanisms. $1^{\text {st }}$ system is a single-story moment frame which has a rigid connection between columns and beams, second study is a three-story moment frame and the last model is a one-story model which has semi-rigid connections between beams and columns.

Fig. 2 presents the comparison between experimental load-displacement curves and finite element analysis results of three different models. $1^{\text {st }}$ and $3^{\text {rd }}$ models were monotonically loaded and compared to the backbone curve of the actual cyclic experiment test results. $2^{\text {nd }}$ model's finite element analysis results were directly compared to the cyclic test envelope curve. Fig. 2 also gives the finite element representations of the test specimens.
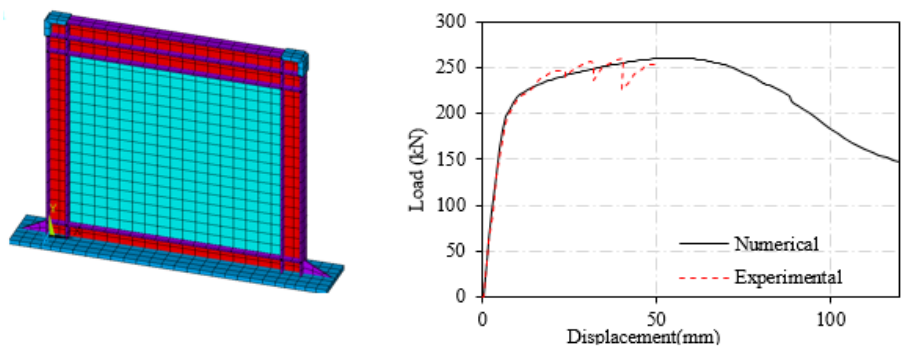

a) Lubell [10]
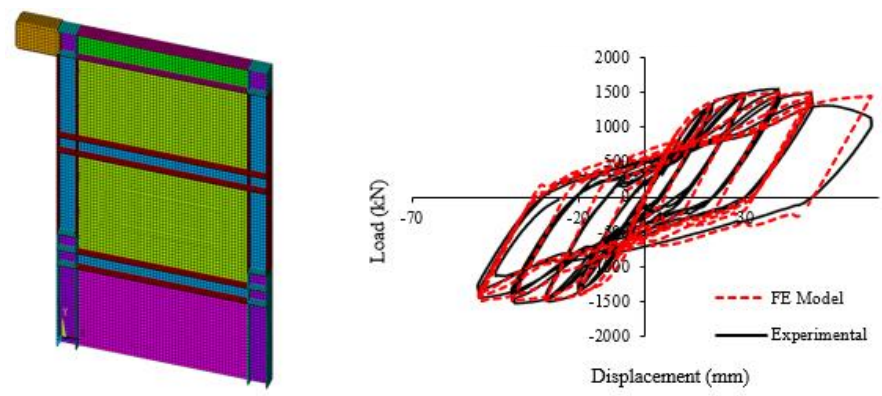

b) Wang et al. [12]
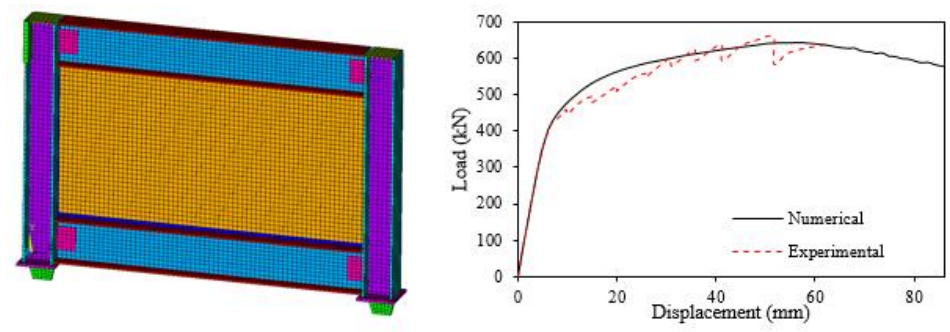

c) Berman and Bruneau [11]

Fig. 2. Finite element models and comparison of numerical and experimental results 
According to the comparison of finite element analysis results and the experimental loaddisplacement curves, it is seen that numerical models were able to revive the measured response. Especially, initial stiffness of the specimens and maximum load carrying capacities of the systems were almost matches with the experimental results. In other words, employed finite element modeling procedure of the steel plate shear walls and the numerical results were satisfactorily validated against the experimental results.

\section{Parametric study on inclination angle}

As described above, tension field inclination angle is one of the parameters used in design of steel plate shear walls. Tension field phenomena adopted by current code provisions [15]. Load resisting capacity of infill plate is determined by using plastic analysis [16]. The base shear resisted by steel infill plate is given as follows:

$V_{p}=0.5 F_{y} t L_{p} \sin 2 \alpha$

where $F_{y}$ is yield strength of infill plate, $t$ is thickness of infill plate, $L_{p}$ is the bay width and $\alpha$ is the tension field inclination angle. In this study, by using finite element analysis, the effects of the parameters were investigated. Inclination angles were calculated at three different locations of the steel plate web which are the closest plate elements to the upper beam, closest plate elements to the lower beam and the elements at middle height of the plate. Principal stresses plotted and angle values

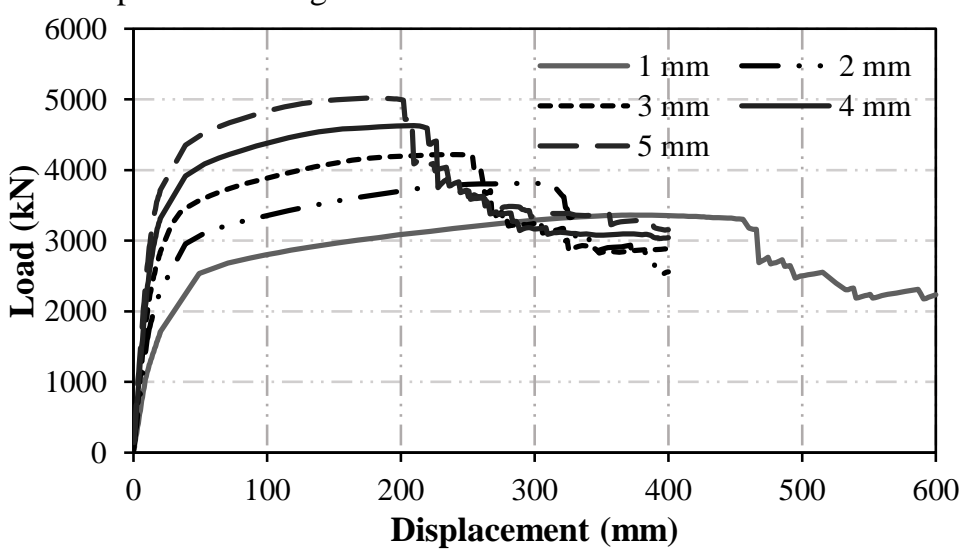

Fig. 4. Load - displacement curves of the models that have different plate thicknesses. vectors. taken from randomly selected points and averaged at the end. Fig. 3 demonstrates the inclination angles from randomly selected points on plotted principal stresses.

\subsection{Effect of web plate thickness}

Web plate thickness effect on the calculation of the inclination angle was studied. A certain geometry selected as the control model. Steel web plate thickness has a width of $4000 \mathrm{~mm}$ and height of $2800 \mathrm{~mm}$. Boundary elements were designed as Canadian Standards W360x179 beams [17]. Selected web plate thicknesses are $1 \mathrm{~mm}, 2 \mathrm{~mm}, 3$ $\mathrm{mm}, 4 \mathrm{~mm}$ and $5 \mathrm{~mm}$. All models were analyzed separately and load - displacement curves are given in Fig. 4.

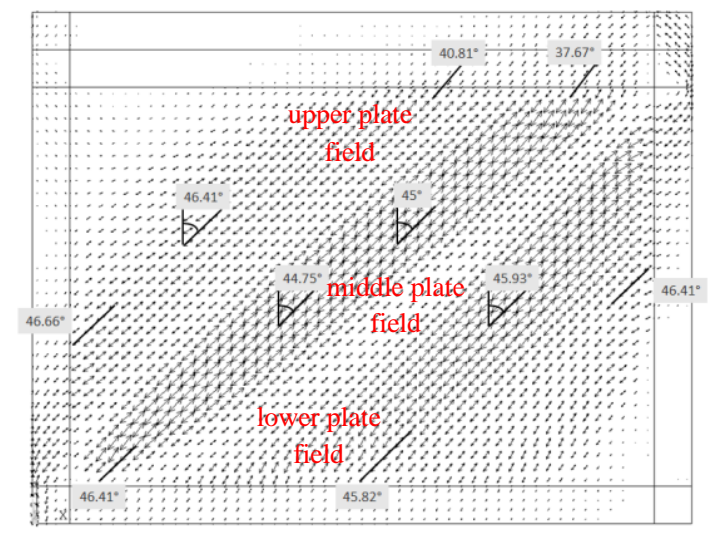

Fig. 3. Angle between vertical and first principal stress 
As expected, maximum load capacity increased with increasing plate thickness. On the other hand, failure of the system was occurred at lower displacements in thicker plates. Failure mechanism of the models were column global buckling and local buckling of column flanges. Thicker plates lead columns to buckle earlier, thus the SPSWs with thicker plates exhibits less ductility. Fig. 5 represents averaged principal stress inclination angles of randomly selected points. Inclination angles calculated at the end of the linear region of load-displacement curves and when maximum capacity is reached.

Acquired results show that changing plate thickness causes fluctuations at inclination angles calculated from low plate and high plate fields, but inclination angles show a stable behavior at middle plate fields. Also, variation in plate thickness does not significantly affect the inclination angle.

\subsection{Effect of boundary elements}

Another parameter that is used for calculation of inclination angle is the boundary element moment of inertias. To examine the effect of this parameter on inclination angle, models were created with a width of $4000 \mathrm{~mm}$ and height of $2800 \mathrm{~mm}$. Different boundary element moment of inertias were selected to study effects on inclination angle. Load-displacement curves of different sections are plotted at Fig. 6 and dimensions of different boundary elements are presented in Table 1 .

From low to high cross-sectional areas, W310x74, W250x89, W360x122 and W360x179 sections are used for models. Selected sections were analyzed with same $3 \mathrm{~mm}$ thick steel plate. Analysis results show that tension field inclination angle is not very sensitive to boundary element cross sectional area or moment of inertias. Calculated principal stress inclination angles are presented in Fig. 7.

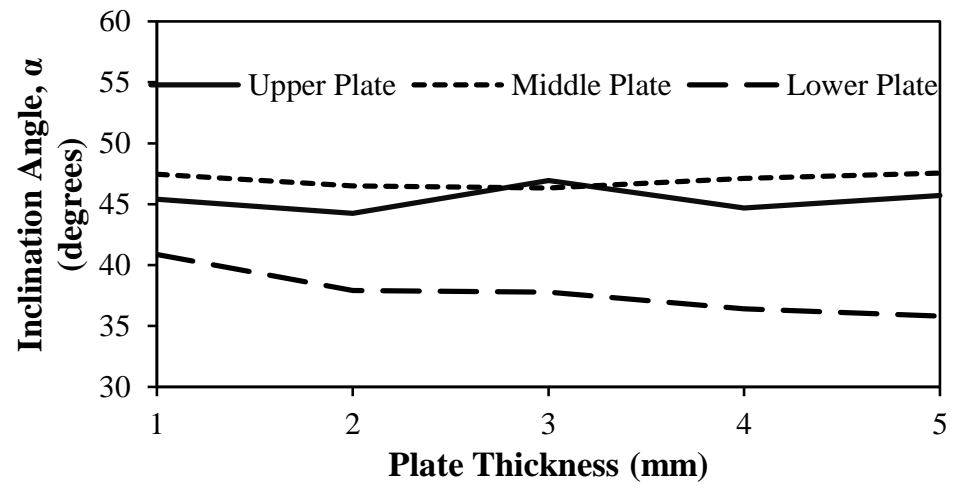

Fig. 5. Averaged inclination angles of the models at maximum capacity.

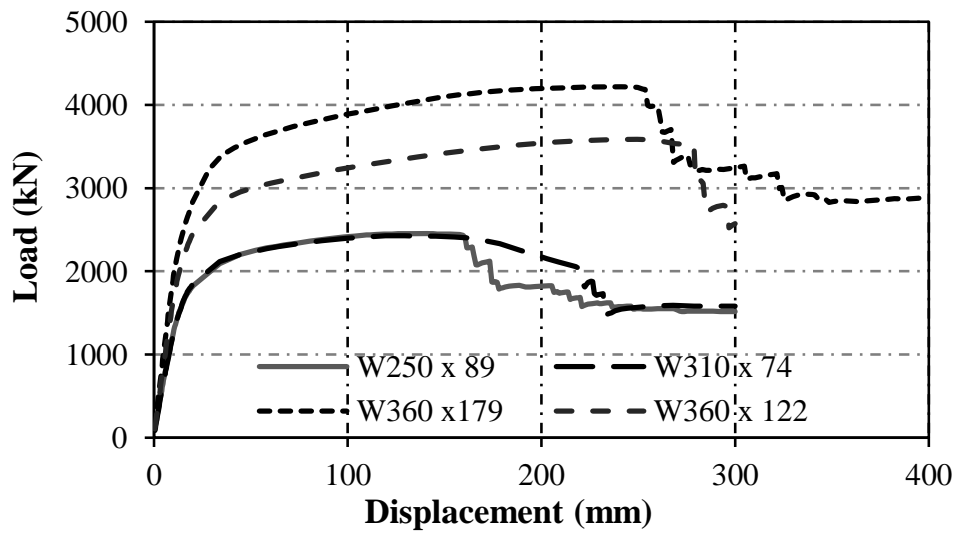

Fig. 6. Load - displacement curves of the models with different boundary elements. 
Table 1. Boundary element properties

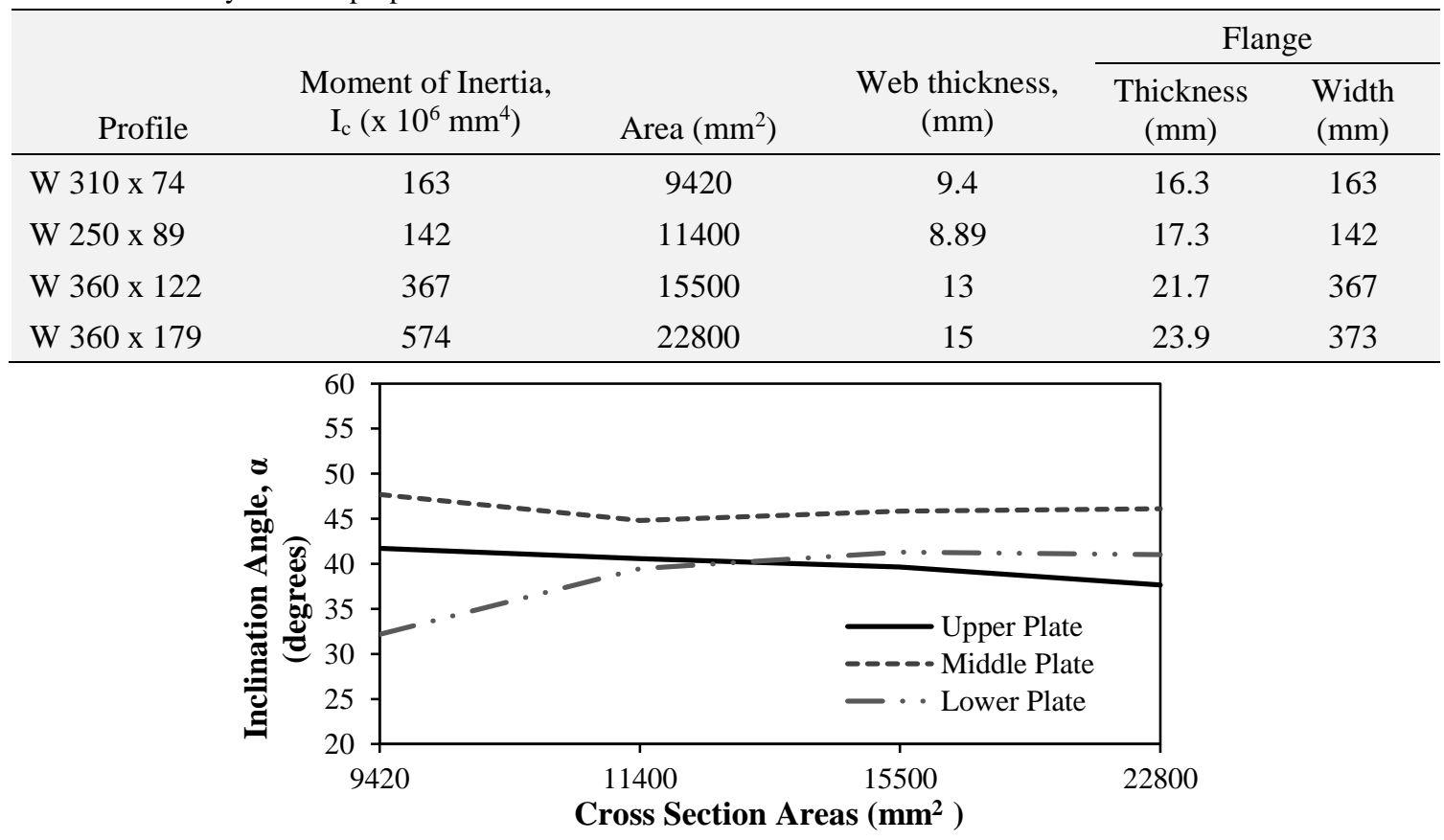

Fig. 7. Inclination angles of the models with different cross section areas.

According to the results, it can be concluded that inclination angles at the middle plate field are concentrated around $45^{\circ}$. Approximately, an inclination angle of $40^{\circ}$ is observed around low and high plate fields.

\subsection{Effect of aspect ratio $(L / h)$}

Last parameter was selected as aspect ratio of the steel plate shear wall. To investigate the correlation between steel plate aspect ratio and inclination angle, one story and two-story models were created. Fixed $\mathrm{L}=4000 \mathrm{~mm}$ plate length was defined for the models and only heights (h) were changed to attain different aspect ratios.

When calculating the tension field inclination angle, all stress values of all nodes at mid plate field were considered. Moreover, tension field inclination angle trend near the vertical boundary elements was investigated. Fig. 8 demonstrates the three fields that tension field inclination angles were calculated separately.

Middle height of the web plate was divided into three fields, which are left column field, middle plate field and right column field. On the models, the tension side, on which the prescribed displacement loading is applied, is named as "left column side". Fig. 9 shows calculated inclination angle of all three fields with different aspect ratios. At very low drift levels, tension field inclination angle has a dramatic fluctuation at the left and right column fields. However, tension field inclination angle showed less fluctuation at the middle plate field. Tension field inclination angle became more stable after 0.01 drift ratio. When the drift ratio is less than 0.01 , no reliable angle variation was observed. At the near vicinity of boundary elements local stresses dramatically changes. Therefore, calculated inclination angles does not give usable results.

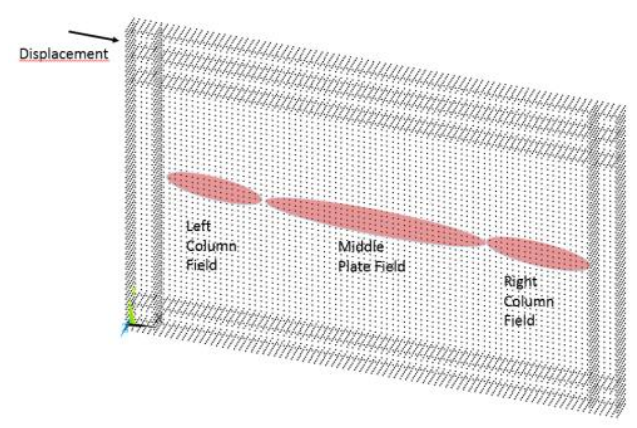

Fig. 8. Separated tension fields of web plate 


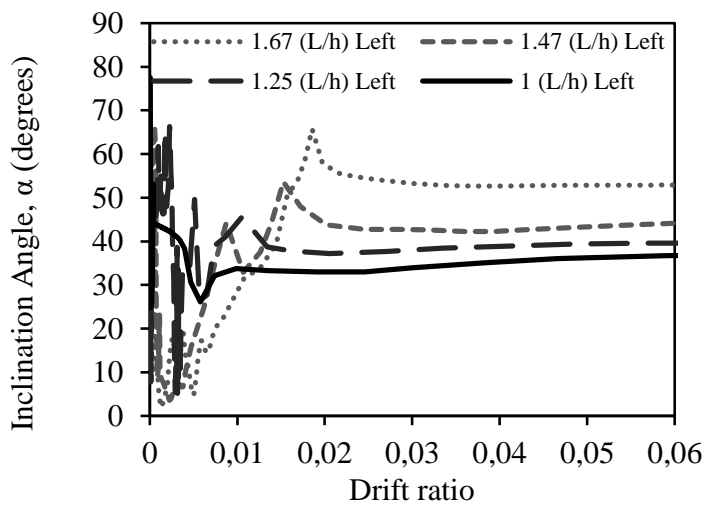

a) Left column field

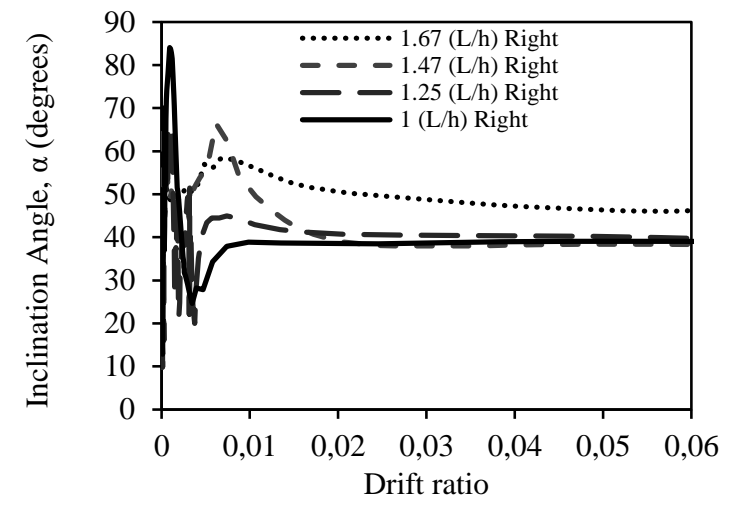

b) Right column field

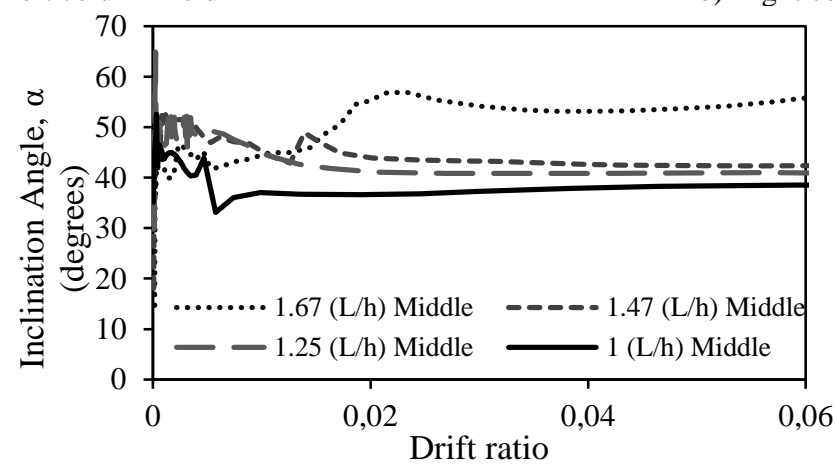

c) Middle plate field.

Fig. 9. Calculated inclination angles of three different fields

For two-story models, inclination angles of first story is considered. Likewise, one story models, web plate is assumed to be divided into three different fields and denotation is same as one story case. Tension field inclination angles are similar to those in one story models. Inclination angles that are calculated below the 0.01 drift ratio vary excessively. Inclination angles are concentrated about $40^{\circ}$ beyond 0.01 drift ratio. Fig. 10 shows the calculated inclination angle of all three fields for walls with different aspect ratios on two story models.

The tension field inclination angles on both oneand two-story frames take almost a constant value after 0.01 drift ratio. In both cases, tension field inclination angle takes larger values with increasing $\mathrm{L} / \mathrm{h}$ ratio. Also, the tension field inclination angle changes in between $35^{\circ}$ and $45^{\circ}$.

\section{Results}

Parameters that are used in calculation of inclination angle are studied numerically by using finite element models and conducting non-linear analyses. According to results, variations in web plate thickness does not affect the inclination angles especially on the horizontal middle field of the plate. The inclination angles are concentrated around $45^{\circ}$ at the middle plate field of the web. Likewise, studying boundary element cross sectional area and moment of inertia showed that inclination angles at the middle web plate field are not very sensitive to mentioned boundary element parameters. Inclination angle values are about approximately $45^{\circ}$ at the middle web plate field. However, according to numerical study results, aspect ratio is an effective parameter on the inclination angle. Lower aspect ratio causes inclination angles to decrease. This behavior is observed on both one- and two-story models. 


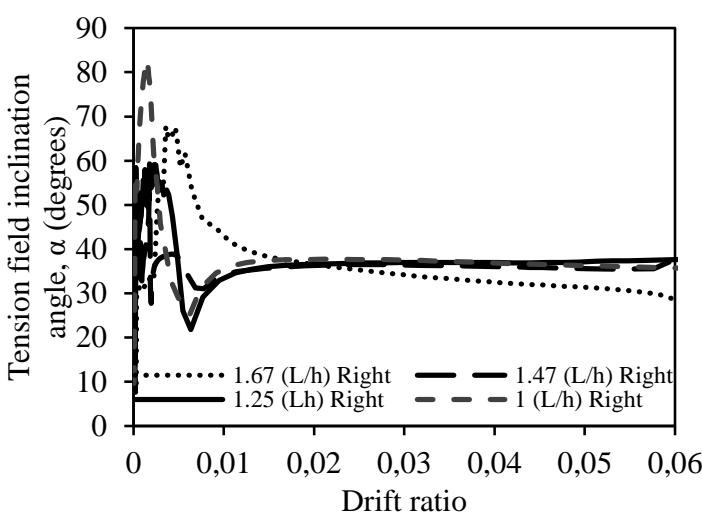

a) Right column field

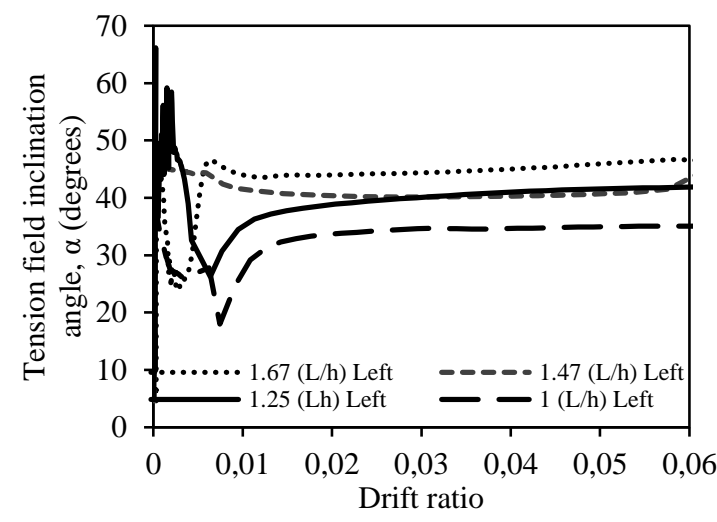

b) Left column field

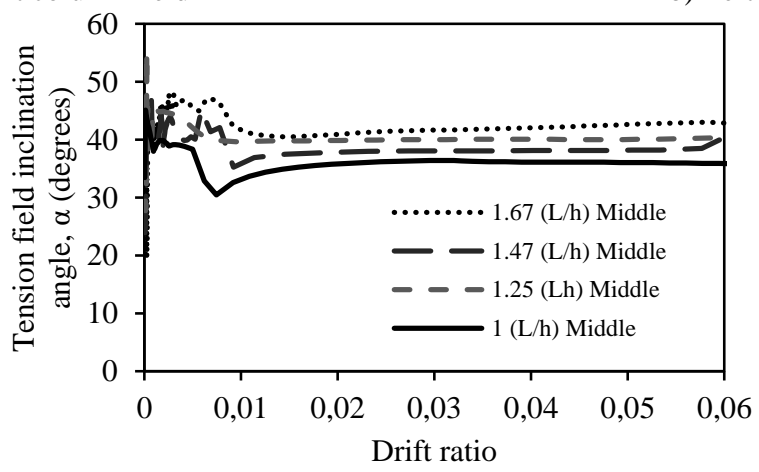

c) middle plate field

Fig. 10. Tension field inclination angles of two-story models

Moreover, below 0.01 drift ratio, inclination angle is not stable and a representative value cannot be recommended. Fluctuations below this drift ratio is very high. Beyond 0.01 drift ratio, which may be associated with the yielding of the developed tension strut, inclination angle displays a more stable behavior.

\section{References}

[1] Berman JW, Bruneau M (2004) Steel plate shear walls are not plate girders. Engineering JournalAmerican Institute of Steel Construction 41: 95106.

[2] Timler PA, Kulak GL. Experimental study of steel plate shear walls. Department of Civil Engineering, University of Alberta, Alberta, Canada, 1983.

[3] Elgaaly M, Caccese V, Du C (1993) Post-buckling behavior of steel-plate shear walls under cyclic loads. Journal of Structural Engineering 119(2): 588-605.

[4] Driver RG, Kulak GL, Elwi AE, Laurie Kennedy DJ (1998) FE and simplified models of steel plate shear wall. Journal of Structural Engineering 124(2): 121-130.

[5] Rezai M. Seismic behavior of steel plate shear walls by shake table testing. $\mathrm{PhD}$ Thesis. University of British Columbia, 2000.

[6] Kharrazi MHK. Rational method for analysis and design of steel plate walls. PhD Thesis. University of British Columbia, 2005.

[7] Choi IR, Park HG (2009) Steel plate shear walls with various infill plate designs. Journal of Structural Engineering 135: 785-796.

[8] Ozcelik Y, Clayton PM (2017) Strip model for steel plate shear walls with beam-connected web plates. Engineering Structures 136: 369-379.

[9] Wei MW, Liew JR, Yong D, Fu XY (2017) Experimental and numerical investigation of novel partially connected steel plate shear walls. Journal of Constructional Steel Research, 132: 1-15.

[10] Lubell AS. Performance of unstiffened steel plate shear walls under cyclic quasi-static loading. $\mathrm{PhD}$ Thesis. University of British Columbia, 1997. 
[11] Berman JW, Bruneau M (2005) Experimental investigation of light-gauge steel plate shear walls. Journal of Structural Engineering 131(2): 259-267.

[12] Wang M, Shi Y, Xu J, Yang W, Li Y (2015) Experimental and numerical study of unstiffened steel plate shear wall structures. Journal of Constructional Steel Research 112: 373-386.

[13] Applied Technology Council (ATC). Guidelines for cyclic seismic testing of components of steel structures, 1992.
[14] APDL, ANSYS Mechanical, release 14.0, ANSYS Ltd, 2012.

[15] AISC, ANSI. AISC 341-05. Seismic provisions for structural steel buildings. Chicago (IL): American Institute of Steel Construction, 2005.

[16] Berman JW, Bruneau M (2003) Plastic analysis of steel plate shear walls. Journal of Structural Engineering 129(11): 1448-1456.

[17] Canadian Standards Association, CAN/CSA-S1601. Limits States Design of Steel Structures, Standards Council of Canada, Canada, 2001 